\title{
Percepción sobre la seguridad ciudadana en Sonora
}

\section{Perception of Citizen Security in Sonora}

\author{
Guadalupe Tejeda Parra* (1) https://orcid.org/0000-0003-4969-5731 \\ Carlos Germán Palafox Moyers ${ }^{* *}$ (i) https://orcid.org/0000-0002-6306-4744
}

\section{Resumen}

Objetivo: analizar la percepción que tienen los habitantes de Sonora sobre la seguridad ciudadana en su estado. Metodología: se utiliza el método logit dicotómico. Resultados: se encontró que haber sufrido alguna agresión física o recibido alguna amenaza, así como vivir con una persona con problemas de drogas, afecta de manera negativa la percepción sobre la seguridad ciudadana, mientras que participar en una asociación de vecinos, al igual que la satisfacción que expresan las personas con su colonia, ciudad y país, tiene un efecto positivo en dicha percepción. Limitaciones: puesto que el tema de la seguridad es multifactorial, es muy probable que la propuesta metodológica haya dejado fuera variables significativas durante el análisis. Valor: el enfoque regional aporta utilidad al conocimiento sobre esta problemática actual y permite plantear nuevas propuestas sobre el rumbo $u$ orientación hacia soluciones. Conclusiones: la seguridad ciudadana es un tema que trastoca no sólo un aspecto de la vida de las personas; también incide en su bienestar general. Por lo tanto, requiere abordajes integrales y no unidireccionales.

Palabras clave: seguridad ciudadana; percepción; bienestar; Sonora.
\end{abstract}

\begin{abstract}
Objective: to analyze the Sonoran's perception of citizen security in their state. Methodology: the dichotomous logit method is used. Results: it is found that having suffered some physical aggression or received some threat, as well as living with a drug-problem person, negatively affect the perception of citizen security, while participating in a neighbors association and people expressing their satisfaction about their neighborhood, the city and the country, pay positively in that perception. Limitations: since the issue of safety is multifactorial, the methodological proposal could have left out significant variables from the analysis. Value: the regional approach provides useful knowledge about this current problem, allowing the raise of new proposals on the direction or orientation of solutions. Conclusions: citizen security is an issue that not only disrupts an aspect of people's lives, but also impacts their general well-being; therefore, it requires comprehensive approaches and not only unidirectional ones.
\end{abstract}

Keywords: citizen security; perception; well-being; Sonora.

Cómo citar: Tejeda Parra, G., y Palafox Moyers, C. G. (2021). Percepción sobre la seguridad ciudadana en Sonora. región y sociedad, 33, el438. doi: I0.22198/rys2021/33/1438

*Autora para correspondencia. Universidad de Sonora, Departamento de Economía. Blvd. Luis Encinas y Rosales s. n., col. Centro, C.P.83000. Hermosillo, Sonora, México. Correo electrónico: guadalupe.tejeda@unison.mx

** Universidad de Sonora, Departamento de Economía. Blvd. Luis Encinas y Rosales s. n., col. Centro, C.P. 83000. Hermosillo, Sonora, México. Correo electrónico: economia@guaymas.uson.mx

Recibido: 14 de enero de 2021

Reevaluado: 19 de mayo de 2021

Aceptado: 28 de junio de 2021

Liberado: 7 de septiembre de 2021 


\section{Introducción}

Según la Organización Mundial de la Salud (OMS), cada año más de 1.4 millones de personas pierden la vida debido a la violencia. Por cada una que muere, muchas quedan con lesiones y diversos problemas de salud física, sexual, reproductiva y mental. La violencia supone una enorme carga para las economías nacionales, con un costo de miles de millones de dólares anuales en atención sanitaria, vigilancia del cumplimiento de la ley y pérdida de productividad (OMS, 2002).

En 2000, el mundo registró 1659000 muertes por causas violentas, de las cuales $90 \%$ ocurrió en países de bajos a medianos ingresos, entre ellos, los latinoamericanos (Garmendia, 2011). En particular, el continente americano suma $37 \%$ de los homicidios registrados en todo el mundo. La mayoría de ellos ocurre en América Latina, donde se concentra $8 \%$ de la población mundial (Lissardy, 2019). El tema de la seguridad en dicha región se ha considerado un asunto central y prioritario en la agenda política y pública debido al aumento de la tasa de delitos, pues, según CAF-Banco de Desarrollo de América Latina (CAF, 2014), "la cotidianidad del ciudadano latinoamericano está marcada por la inminencia latente de ser la próxima víctima” (p. 17).

En México, 2019 fue el año con más asesinatos en las últimas dos décadas, lo que representa un aumento de $2.5 \%$ con respecto a 2018. De acuerdo con el Secretariado Ejecutivo del Sistema Nacional de Seguridad Pública (SNSP), entre enero y diciembre de 2019 se cometieron en el país 34582 homicidios dolosos, la mayor parte de ellos en los estados de Guanajuato, Estado de México, Michoacán, Jalisco y Baja California. Según las estadísticas, junio de 2019 fue el mes con más homicidios: 2993 (Secretariado Ejecutivo, 2020).

Los problemas de inseguridad tienen orígenes multifactoriales y multicausales. Diversos enfoques buscan analizar el problema social de la violencia y de la inseguridad y dar respuesta a este grave fenómeno. Clarke y Cornish (1985), Sutton y Álvarez (2017) argumentan que la desigualdad social es uno de sus principales detonantes. La CAF (2014) y González (1998) plantean que el deterioro y el crecimiento urbanos, junto con los altos niveles de desempleo, crisis económicas y debilitamiento de las instituciones del Estado, son los principales detonadores de la violencia. García y Quintana (2015), Insulza (2014) y Jaitman (2015) proponen que existen variables que inciden de forma directa en la criminalidad y en los niveles de violencia, como la intrafamiliar, las pandillas, la delincuencia organizada, las armas, las drogas y el consumo de alcohol. Para San Martín (2012) y Sutton y Álvarez (2017), la pérdida de valores y principios en el núcleo familiar y en el entorno local es lo que incrementa la violencia y la criminalidad.

En ese contexto, el enfoque de seguridad pública utiliza la fuerza del Estado para enfrentar la violencia y el crimen con el fin de mantener el orden público. Las estrategias de seguridad se sustentan en las acciones de carácter punitivo sin considerar o restando importancia a otros aspectos que pudieran estar relacionados directamente con el bienestar de las personas. En cambio, el enfoque de seguridad ciudadana junto con el de derechos humanos, que es 
el que se utiliza en la presente investigación, centra la atención en el bienestar de la ciudadanía. La seguridad es elemento crucial en la calidad de vida de las personas. Desde esta perspectiva, el espacio inmediato de la colonia y la ciudad se convierten en elementos significativos para el estudio. Así mismo, se ha elegido el análisis regional. Se ha seleccionado para ello el estado de Sonora, bajo el conocimiento de que existen problemas específicos sobre la percepción de seguridad en la entidad (Aldana y Ramírez, 2012), lo cual enriquece el estudio de los temas de seguridad en general.

Se utiliza un modelo econométrico mediante el método logit dicotómico, que busca presentar los determinantes de la satisfacción con la seguridad ciudadana en la población sonorense. El método evalúa la probabilidad de que una persona valore su satisfacción con la seguridad ciudadana -que toma el papel de variable dependiente- en satisfecha o insatisfecha como una función de un conjunto de valores, es decir, definida a través de características de las variables explicativas o independientes, a saber: las personas que han declarado haber sufrido una agresión física o alguna amenaza en el hogar; la pertenencia de algún miembro del hogar a una organización de vecinos; si alguna persona del hogar sufre drogadicción; el nivel de satisfacción con el barrio, la ciudad y el país; sexo y estado civil. Los resultados del modelo econométrico se ajustan de manera apropiada a los datos, ya que existe relación entre las variables explicativas y la seguridad ciudadana. Por lo tanto, las variables seleccionadas se adecuan a la estimación de probabilidades.

El artículo tiene seis apartados, además de la presente introducción. El primero analiza los enfoques de seguridad pública y de seguridad ciudadana, sus diferencias y sus formas de enfrentar la problemática social de la violencia. En el segundo se analizan los componentes de la seguridad ciudadana desde la óptica del bienestar; en particular, se examina la percepción, el entorno, la territorialidad, los lazos comunitarios y el problema de las drogas. El tercero presenta algunas características del contexto en que se desenvuelve la seguridad ciudadana en Sonora. En el cuarto apartado se encuentra la propuesta metodológica de un modelo econométrico mediante el método logit dicotómico sobre los determinantes de la satisfacción con la seguridad ciudadana en la población sonorense. El apartado cinco expone los resultados del modelo econométrico. El último presenta las conclusiones.

\section{Nueva forma de abordar la seguridad ciudadana}

El abordaje teórico de la seguridad, así como de sus contrapartes, la inseguridad, la criminalidad y la violencia, es amplio y rico en contribuciones. La seguridad es un tema cuya construcción social es permanente y se la ha relacionado con otros conceptos, a saber: "seguridad nacional, pública, integral, humana, ciudadana” (García y Quintana, 2015, p. 53).

Según García y Quintana (2015), existen dos enfoques respecto a la forma de conceptualizar la seguridad: uno en referencia al concepto de policía, en el que las instituciones policiales son la única o la principal vía para la resolución 
o la contención de los conflictos y de la delincuencia en la sociedad; el otro enfoque establece que los conflictos, y en especial el aumento de los delitos, son consecuencia del crecimiento de la pobreza, de la marginalidad o de la desintegración social. Por lo tanto, en este enfoque es necesaria una intervención integral para solucionar el problema de la inseguridad.

En el mundo, los fenómenos de violencia y de inseguridad han visto el tránsito de un modelo de seguridad pública a uno de seguridad ciudadana y derechos humanos. El primero enfoca la represión como elemento central en el combate al crimen, mientras que el segundo es incluyente y se basa en los derechos humanos. Busca incorporar a las víctimas y a los victimarios en la comprensión del delito. Se basa en un concepto ampliado de seguridad, con una participación más activa de las comunidades, en el cual las políticas tengan como finalidad a las personas y su desarrollo (Dammert, 2005), pues tener como punto central en la seguridad ciudadana una política punitiva, enfocada en el victimario, excluye del análisis a la víctima, quien ha visto vulnerados sus derechos humanos (CAF, 2014) y su bienestar general. Desde este marco, la seguridad ciudadana tiene diversas implicaciones para el bienestar de las personas, ya que "es un determinante fundamental del bienestar de los hogares y las comunidades" (CAF, 2014, p. 3).

No se está proponiendo dejar de lado la lucha contra la delincuencia. El análisis para la contención del delito se enfoca en el control y la represión. Además, presenta nuevas orientaciones y formas de actuación, como el desarrollo educativo y socio-emocional. Se busca relacionar la seguridad ciudadana con el desarrollo social, con el entorno y con el concepto de bienestar; es decir, con el desarrollo integral de las familias y las comunidades.

\section{Componentes de la seguridad ciudadana}

Esta forma de interpretar la seguridad ciudadana da primacía a la vida y a la dignidad humanas. Es una concepción ciudadano-céntrica, que se aleja y supera la definición clásica centrada en el poder y el dominio estatal, o sea, una visión estatocéntrica (Ramos, 2005). Varios estudios, aunque tienen diferentes metodologías y objetivos, comparten la idea general de que el crimen y la violencia tienen consecuencias que llevan a la pérdida del bienestar. Por ejemplo, Jaitman (2015) documentó los costos del crimen y la violencia en el bienestar. Para la autora, dichos costos se pueden enmarcar en dos dimensiones. La individual toma en consideración el valor de los bienes robados o el temor que experimenta la víctima de un delito. Y la social se relaciona con el gasto público para prevenir y erradicar esas problemáticas.

En América Latina se han emprendido acciones para la seguridad ciudadana. Un caso particular es Colombia, donde la criminalidad y la violencia han aumentado tanto desde 1970, que se ha convertido en uno de los países con las tasas más altas de violencia en el mundo (Salazar y Castro, 1998). Con el fin de prevenir y controlar esta problemática, el gobierno nacional y el Banco Interamericano del Desarrollo (BID) han creado el Programa de Convivencia y Seguridad 
Ciudadana, que presenta una doble orientación de la seguridad ciudadana, una combinación entre la prevención y el control. Por un lado, está el control de la criminalidad a través de la represión y, por el otro, la prevención de la violencia y el desarrollo de la convivencia en las ciudades.

Dammert, Mujica y Zeballos (2017) realizaron un estudio en Perú que perseguía dos objetivos. En primer lugar, mostrar la investigación producida en áreas relacionadas con la seguridad ciudadana entre 2011 y 2016. En segundo lugar, consolidar una agenda de investigación sobre ésta a futuro. Para el segundo objetivo, seleccionaron 16 investigadores en la materia ${ }^{1}$ que consideraron ocho temas relevantes para el análisis: homicidio, violencia contra la mujer, delitos patrimoniales, crimen organizado, sistema de justicia, percepción de inseguridad, respuestas frente a la inseguridad y otras formas de violencia. En el tema de la percepción de inseguridad, las áreas prioritarias de estudio fueron las tendencias en la percepción de inseguridad, las relaciones entre la percepción de inseguridad y la victimización y las causas de dicha percepción.

Siguiendo la Encuesta de Cultura Ciudadana (ECC), Aldana y Ramírez (2012) presentan los cuatro problemas principales de seguridad y convivencia ciudadana en la región: la violencia homicida, la crisis de convivencia, el narcotráfico y la percepción de seguridad ciudadana. El estudio se realizó en ocho ciudades de la región. ${ }^{2}$ En relación con los homicidios, se concluye que América Latina es el área que concentra el mayor número de casos a escala mundial. En la convivencia, entendida como la capacidad de vivir bien en comunidad y crear relaciones entre ciudadanos con base en el respeto mutuo, los dos problemas sobresalientes son la presencia de vecinos ruidosos y las riñas entre borrachos. El narcotráfico queda catalogado como uno de los principales problemas de América Latina en términos de seguridad. Así mismo, la encuesta revela la intolerancia a ciertos grupos de personas: drogadictos, alcohólicos, prostitutas y homosexuales. En cuanto a la percepción, se concluye que cada ciudad muestra problemas específicos de seguridad. ${ }^{3}$

Además, ese estudio revela que la agresión física, es decir, la victimización, ya sea directa o indirecta, es el segundo tipo de delito en nivel de importancia en las ocho ciudades analizadas. De entre ellas, sobresale de manera significativa el Distrito Federal (D. F.), porque tiene los porcentajes más altos. Le sigue la ciudad de La Paz, ambas en México.

\section{Percepción}

Según la CAF (2014), "aunque no todo el mundo haya sido víctima directa de la inseguridad, todo el mundo la padece" (pp. 45-46). Ya sea a través de una experiencia personal o como una percepción de amenaza, la seguridad de las

1 Para el criterio de selección, se consideró que los entrevistados tuvieran al menos cinco años de experiencia especializada (publicación científica o publicación de datos o experiencia pública o internacional) en algún tema relacionado con el crimen, la violencia o la inseguridad en el Perú.

2 Tres ciudades de México: La Paz, Monterrey y el Distrito Federal (ahora Ciudad de México); dos ciudades de Colombia: Bogotá y Medellín; Quito, Ecuador; Caracas, Venezuela; y Belo Horizonte, Brasil.

3 Ese tema, con los mismos autores, se incluye y se analiza con mayor profundidad en la sección "Entorno y territorialidad". 
personas resulta trastocada. El crimen está compuesto de diversas dimensiones y no sólo de los acontecimientos delictivos (González, 1998). Siguiendo a Gudiño (2001, p. 1), la seguridad no se reduce a la ausencia de eventos delictivos, sino que está unida a la percepción de certeza en la vida, la salud y la libertad, entre otros aspectos de valor para las personas. En ese contexto, el estudio de la criminalidad debe tratar dos aspectos prioritarios en las agendas de los países: por un lado, el aumento de los delitos y, por el otro, la sensación de inseguridad de la población (Dammert, 2005).

La percepción se refiere al aspecto subjetivo de la inseguridad (Gudiño, 2001), la cual, a veces, es independiente del hecho de haber padecido un acto delictivo. Es una dimensión en la que todas las personas pueden ser afectadas, pues hace referencia a la percepción o a la posibilidad de ser víctima de un delito. Por otro lado, la dimensión objetiva está basada en la seguridad real, es decir, en los hechos reales (García y Quintana, 2015).

González (1998), cuando define la seguridad pública, distingue entre una dimensión objetiva-cuantitativa, que se refiere a una situación de probabilidad de ser víctima de un delito, y una dimensión subjetiva-cualitativa, que expresa la percepción de la posibilidad de sufrir un delito. San Martín (2012) valora la percepción de la seguridad ciudadana a partir del lugar de residencia, la cercanía a bienes y servicios, además de las diferencias demográficas entre los sectores rurales y urbanos.

De manera general, la evidencia empírica muestra que la parte subjetiva de la inseguridad es mayor a las tasas de victimización real, esto es, no está relacionada de forma directa con las experiencias personales; puede estar propiciada por las experiencias de terceros o por el temor a ser víctima (González, 1998). Se construye de manera directa a través de las experiencias vividas y, al mismo tiempo, de manera indirecta a través de experiencias "secuestradas" en relación con las condiciones del entorno, en el ámbito institucional, moral, político y mediático.

Pegoraro (2002) distingue entre dos tipos de inseguridad, la objetiva y la subjetiva. La primera se refiere a la probabilidad de ser víctima de un delito y está relacionada con la edad y el género. La segunda se refiere al miedo de ser víctima de un delito, lo cual está influido casi siempre por las noticias que presentan los medios de comunicación que producen pánico social.

De acuerdo con Arriagada y Godoy (2000), la seguridad ciudadana se determina por distintas dimensiones y niveles, en especial por su intangibilidad y carácter subjetivo. De manera amplia, las autoras la definen como la preocupación por la calidad de vida y la dignidad humana, en términos de libertad, de acceso al mercado y a oportunidades sociales.

Según Escobar, Muniz, Sanseviero, Saín y Zacchiet (2005), algunos estudios de victimización han logrado construir indicadores para el temor, con lo cual abarcaron una dimensión subjetiva de la seguridad. Por lo general, se observa que la tasa efectiva de delitos es inferior a los niveles de inseguridad o temor que manifiestan las personas. En este sentido, los medios de comunicación desempeñan un papel importante, pues se convierten en reforzadores de las percepciones negativas porque actúan como acusadores sociales. 
Martínez, Ávila, Vera, Bahena y Musitu (2016) establecen un vínculo entre la satisfacción con la vida y la percepción de inseguridad, la victimización y los cambios o restricciones en las rutinas de las personas. Relacionan el bajo nivel de satisfacción con la vida con tres aspectos: haber sido víctima de la inseguridad, la percepción de ésta en espacios públicos y la implementación de medidas de protección física o restricciones en las actividades cotidianas de las personas.

Para Aldana y Ramírez (2012), en el mundo, la tendencia al temor a ser victimizado va en aumento, lo que se vincula a la parte subjetiva de la seguridad. Sin embargo, esta percepción se basa también en aspectos objetivos. En otras palabras, se conforma de las condiciones reales de inseguridad (como la delincuencia, la violencia o la victimización directa o indirecta) y de los miedos o imaginarios colectivos relacionados con ciertos lugares o grupos de personas.

Entorno y territorialidad

En esta forma de abordar la seguridad ciudadana, es importante considerar el estudio de las características tanto físicas como sociales del contexto o entorno donde se desenvuelven las personas (CAF, 2014). Además de la personalidad, de la educación y de las oportunidades laborales, rasgos que pueden influir en la comisión de un delito, también se encuentran otros aspectos relacionados con el entorno físico y social: la atractiva participación económica en los mercados ilegales y no la confianza en las instituciones de justicia penal, entre otros.

Así, el entorno donde se vive a diario, es decir, la calle, el vecindario o la colonia, es un foco indicativo del crimen, pues según los datos del CAF (2014) se ha encontrado que una gran proporción del delito se concentra en un reducido número de calles o cuadras. Esta concentración se expresa como un desorden físico; por ejemplo, ventanas rotas y terrenos baldíos. También puede manifestarse como un desorden social: prostitución, mendicidad y riñas.

Se busca explicar la aparición y la consolidación de procesos de territorialización a partir del territorio y del entorno, el primero entendido como el espacio físico y sus componentes geográficos; el segundo, como aquellos factores precursores de inseguridad desde el punto de vista histórico, económico, social, político y cultural que condicionan, facilitan o contribuyen a consolidar esos procesos.

Todo evento criminal se compone de la persona que lo efectúa y de la situación en que se lleva a cabo (CAF, 2014). Esos dos componentes configuran las probabilidades del delito. Por ejemplo, algunas propuestas teóricas toman como punto de referencia el comportamiento del individuo para estudiar los fenómenos asociados con la inseguridad y con la delincuencia. En otros términos, se presenta el sujeto como objeto de análisis. Puede identificarse aquí la teoría de la elección racional o de las decisiones racionales, en la que Clarke y Cornish (1985) plantean que una conducta delictiva es resultado de una decisión racional: quienes cometen actividades que contravienen las normas, buscan beneficios derivados de esa actividad a partir de un análisis de costo y beneficio. Esa 
teoría sostiene que quienes cometen un delito, lo hacen tras un proceso de toma de decisiones (Wilson y Herrnstein, 1998).

El entorno es el lugar físico, el contexto social o la presencia de autoridades policiales, que estimulan o dificultan la comisión de un delito. Según la CAF (2014), "se ha logrado establecer con precisión que el crimen guarda una relación estrecha con el espacio físico" (p. 39). De esta forma, se pueden identificar lugares muy concretos en un mismo vecindario, como las calles o las esquinas, donde de forma preferencial se llevan a cabo actos delictivos.

La teoría de la actividad rutinaria que proponen Cohen y Felson (1979) explica que los rasgos socio-comportamentales repetitivos que suelen adoptar los habitantes o quienes frecuentan zonas críticas y vulnerables, constituyen un factor decisivo a la hora de generar arraigo o pertenencia entre éstos y dichos lugares, hasta el punto de ver el delito, la pobreza, la exclusión, la marginalidad y la nula satisfacción de sus necesidades básicas como algo normal y rutinario. En la teoría se encuentran tres espacios bien delimitados. En el primero están los cambios en las actividades rutinarias de vida diaria. En el segundo, el aumento de las oportunidades y de las tendencias para el delito como resultado de la convergencia en el espacio y en el tiempo de tres elementos: 1) delincuentes motivados; 2) objetos víctimas apropiados y 3) ausencia de protectores eficaces. En el tercer espacio se encuentra el aumento de las tasas de criminalidad.

La teoría de las ventanas rotas que propusieron Wilson y Kelling (1982) constituye uno de los principales soportes teóricos explicativos para el proceso de territorialización. Busca esclarecer la dinámica de la relación causal entre segu$\mathrm{ridad} /$ inseguridad y fenómenos de desorden, indiferencia estatal y ciudadana, decadencia urbana y miedo. Plantea que el delito, en cualquier centro urbano, es mayor en las áreas donde hay descuido, suciedad y maltrato a los bienes privados y públicos, por lo que señala que el crimen y la inseguridad son el resultado inevitable del desorden. En conclusión, el desorden y el deterioro tienen efectos en la delincuencia, que a su vez origina un efecto dominó o un efecto cadena (Martin y Ceballos, 2004).

La teoría del patrón delictivo propone que los delitos no ocurren al azar sino que, por el contrario, hay sectores, barrios o zonas donde se producen más delitos que en otros lugares, es decir, parte de unos patrones o tendencias que los delincuentes traducen en oportunidades para delinquir (Vozmediano y San Juan, 2010). Al respecto, Brantingham y Brantingham (1984 y 1993) crearon un modelo teórico que ayuda a entender la configuración y la distribución geográfica del delito y a identificar patrones de inseguridad en escenarios urbanos territorializados. El modelo sirve de herramienta para construir mapas delictivos y para determinar los factores que coadyuvan o consolidan este tipo de escenarios.

En la década de 1940, Shaw y Mckay (2006) efectuaron experimentos encaminados a conocer y a analizar el comportamiento criminal en la ciudad de Chicago (Sozzo, 2016). El resultado pretendía explicar cómo se originan y se consolidan los núcleos delictivos a partir de la "desorganización social” que se genera, entre otras razones, por las características de una zona, lugar o sector y por el desarrollo urbano que se refleja a través del comportamiento de los habitantes de la calle: las prostitutas, los adictos y los miembros de pandillas (Escobar, 2012). 
Para Mockus, Murraín y Villa (2012), la cultura o las diferencias culturales entre un lugar y otro son un componente importante para explicar el porqué de las variadas tasas de homicidios y suicidios entre países, pues cada cultura regula, interpreta y justifica (o no) los comportamientos de sus miembros de manera propia. En ese tema, Ruiz y Murraín (2012) definen el concepto de cultura ciudadana como "la base conceptual o el enfoque de políticas públicas encaminadas a promover el bienestar de la ciudadanía y la democratización de las ciudades por medio de la transformación de los comportamientos de los ciudadanos" ( $p$. 5). A través del concepto de cultura ciudadana, se pretende identificar particularidades culturales específicas de las ciudades para poder incidir en ellas. Son tres los sistemas o mecanismos reguladores de las conductas de los individuos dentro de una política de cultura ciudadana: la ley, la moral y la cultura. La armonía o la desarmonía entre estos sistemas perfilan el actuar ciudadano en un lugar u otro. ${ }^{4}$

González, Macedo y Tinoco (2014) realizaron una investigación en el Estado de México, con el fin de establecer un observatorio de seguridad ciudadana, con la participación activa de la Facultad de Ciencias Políticas y Sociales de la Universidad Autónoma del Estado de México. Además, la investigación perseguía diversos objetivos particulares. Uno de ellos fue diagnosticar la seguridad ciudadana a través de una encuesta de percepción. Se dividió el estado en cinco regiones, de las cuales se obtuvieron submuestras municipales. Se entrevistó a 1950 ciudadanos. ${ }^{5}$ La encuesta incluía, entre otros aspectos, la percepción o el sentimiento de inseguridad y violencia con respecto al entorno territorial. Se consideraron tres parámetros: el barrio, el municipio y el país. Los resultados muestran los porcentajes de quienes consideraron que en el último año (en el momento de la encuesta) se incrementó la delincuencia: 56.2\% para el barrio, $66 \%$ para el municipio y $79.1 \%$ para el país.

Según Aldana y Ramírez (2012), tanto la percepción subjetiva de la seguridad como la seguridad objetiva contribuyen a crear imaginarios en las comunidades, los cuales se sustentan en el temor y son diferenciados a nivel territorial; es decir, existen problemas específicos de percepción de seguridad. Con lo anterior, y basados en la ECC, mostraron que la violencia se demarca de manera diferenciada de un lugar a otro; por lo tanto, cada ciudad revela problemas específicos de percepción de seguridad, porque en cada una se perciben de forma nítida problemas propios. En otras palabras, cada tipo de violencia afecta de forma particular la percepción de los ciudadanos según la territorialidad.

\section{Lazos comunitarios}

La cohesión en las comunidades, entendida como el sentido de pertenencia de los vecinos a su comunidad a través de la propiedad, se asocia con la reducción de las tasas de criminalidad en algunos vecindarios (Sutton y Godinez, 2017).

\footnotetext{
4 Por ejemplo, en un determinado territorio podría darse la aprobación moral o cultural de acciones ilegales.

5 La encuesta se realizó en octubre de 2011 y contó con un margen de error de 5\%.
} 
Un estudio de Frühling (2003) sobre el modelo de policía comunitaria en América Latina establece que la comunidad tiene un papel fundamental en la solución de los problemas de un barrio. Dicho modelo se enfoca en la prevención, en la que es muy importante la participación ciudadana y no sólo la actuación reactiva de las fuerzas policiales. Los factores relativos al establecimiento de lazos comunitarios son generadores de un ambiente de convivencia pacífica y detonan la satisfacción en la seguridad ciudadana.

Los vínculos entre los vecinos fomentan la participación comunitaria, a la vez que proporcionan confianza y soluciones a los problemas de la comunidad, lo cual ayuda al empoderamiento de las organizaciones locales en la problemática de la inseguridad (San Martín, 2012).

En un estudio del BID que analiza el problema de la violencia en el Caribe, ${ }^{6}$ Sutton y Álvarez (2017) revelan que algunos factores estructurales del vecindario y ciertos aspectos de las relaciones sociales ayudan a predecir el crimen. Así, muestran que las personas que expresaron haber sido víctimas de un delito, tienen mayor probabilidad de que en sus vecindarios se registren niveles altos de desorden físico, como casas y edificios abandonados, o el problema de la basura. Además, tienen mayores probabilidades de tener poca cohesión social, lo cual se expresa, por ejemplo, en poca confianza entre los vecinos.

En su estudio sobre seguridad ciudadana, González, Macedo y Tinoco (2014) muestran el grado de participación ciudadana en las asociaciones, en particular mediante la pregunta: “¿Usted es miembro de alguna agrupación u organización social?” (p. 235), a la que $88.4 \%$ de la población entrevistada respondió de manera negativa. La pregunta se incluyó bajo la premisa de que la participación social activa crea sujetos que buscan alternativas para luchar contra la violencia (González, Macedo y Tinoco, 2014). Otro aspecto en el análisis fue la interacción con los vecinos como componente relacionado con el tejido social que forma estructuras de relación en pro de la ciudadanización. La pregunta fue: “¿Qué tanto cree usted que conoce a sus vecinos?” (238); 47.4\% contestó conocerlos bien y hablar con ellos, mientras que $24.8 \%$ dijo no conocerlos, pero sí hablar con ellos.

El problema de las drogas

En varios países de América Latina la droga ha tenido un papel predominante en la historia de la violencia (CAF, 2014). "La ilegalidad de ciertos mercados guarda especial relación con la seguridad ciudadana porque la violencia es frecuentemente el recurso disponible para resolver los conflictos en los mercados ilegales" (CAF, 2014, p. 43). A saber, existe un control a la entrada de este mercado, tanto en la producción como en la distribución, pues éste produce grandes ganancias económicas. El control se lleva a cabo por medio de la violencia, recurso para resolver cualquier tema ante la imposibilidad de hacerlo mediante instancias legales.

6 En particular, Bahamas, Barbados, Jamaica, Surinam y Trinidad y Tobago. 
Siguiendo a Insulza (2014), la relación entre las drogas y la seguridad ciudadana puede analizarse desde tres diferentes áreas. La primera establece un vínculo entre las situaciones de delito y el consumo de drogas. Aquí es importante observar que dicho consumo puede ser un factor influyente para la realización de los hechos delictivos. En la segunda se encuentra una relación entre las actividades de producción, de comercialización y de consumo final. En esta óptica se consideran todos los aspectos económicos que configuran las drogas en un mercado ilícito. Por último, está la intervención estatal a través de políticas públicas para combatir el consumo de drogas en aras de mejorar la seguridad de los ciudadanos.

El problema de las drogas puede expresarse como una amenaza en varios aspectos de la seguridad de las personas: física, patrimonial, psicosocial, sanitaria, comunitaria y ambiental, que se convierten en problemas de inseguridad, siempre precedidos por la falta o acceso limitado a la educación, la salud, el trabajo formal y la justicia, en términos de derechos humanos (Insulza, 2014). El mercado de la droga representa no sólo una preocupación de índole personal, como los problemas de salud y familiares que tienen los consumidores, sino que se traslada a un ámbito más amplio, el de la vida en sociedad, que ha traído consecuencias de violencia más allá del entorno inmediato.

La confrontación del fenómeno del narcotráfico a través de un sistema punitivo no ha dado los resultados esperados. Por el contrario, la CAF (2014) ha demostrado el incremento en el consumo de la mayoría de las drogas, así como en el número de consumidores: "En el caso de la droga, las ganancias extraordinarias aumentan cuando el Estado sólo se ocupa de combatir su producción y su distribución sin reducir su demanda" (p. 19). De acuerdo con Gudiño (2001), el sistema punitivo no es efectivo para combatir estos delitos; se requiere, además, la construcción de espacios de educación y de salud, enmarcados en un diseño de políticas sociales con un sentido más amplio de la seguridad pública.

Para el caso de México y después de haber medido la violencia a través de la tasa de homicidios en hombres jóvenes, Flores y Phillips (2021) emplearon un modelo econométrico mediante el cual se demostró que la violencia letal se incrementa con las intervenciones militares. Explican los resultados mediante tres factores. En primer lugar, por un componente de estacionalidad de la violencia. Encuentran que la violencia vinculada a las drogas tiene componentes estacionales relacionados con la disputa entre los cárteles por los cultivos de amapola. En segundo lugar, porque compiten entre ellos debido a la escasez de recursos. Los cárteles contienden por el control de los municipios para dirigir rutas de tráfico de drogas, sitios estratégicos y recursos naturales, con el fin de obtener poder y ganancias económicas. En tercer lugar, un componente de gobernabilidad, pues sugieren que la alternancia de partidos en los municipios y a escala estatal (después de 2007) provocó un aumento de la violencia letal, ya que los grupos delictivos eran menos dependientes de la protección que tenían del gobierno, lo cual ha actuado en favor de las actividades delictivas. 


\section{Seguridad ciudadana en Sonora}

Con el fin de ofrecer un contexto que brinde mayores herramientas al análisis de la seguridad ciudadana, se presenta una descripción de los indicadores en dicho tema para el estado de Sonora.

Se utiliza la Encuesta Nacional de Ingresos y Gastos de los Hogares (ENIGH) del Instituto Nacional de Estadística y Geografía (INEGI) como fuente de información primaria para el año 2014 (INEGI, 2015a). En especial, se emplea el Módulo de Bienestar Autorreportado (BIARE) que acompaña al Módulo de Condiciones Socioeconómicas (MCS) de la ENIGH (INEGI, 2013, 2014 y 2015b). ${ }^{7} \mathrm{El}$ BIARE es una encuesta con representatividad nacional y por entidad federativa para la población mayor de 18 años, que incluye temas acerca del bienestar subjetivo de las personas, sus dominios - como la seguridad ciudadana-, sus condicionantes y su contexto, mientras que el MCS brinda información socioeconómica de los hogares, así como de sus integrantes.

Siguiendo la metodología del INEGI, la muestra del BIARE quedó conformada por 44518 registros, de los cuales se lograron recabar 39274 cuestionarios. Para la presente investigación se ha seleccionado a la población residente en el estado de Sonora. Se trabajó con una muestra de 1260 personas a nivel de microdatos, que también se cruzaron con los datos del MCS para obtener un mayor rango de información. ${ }^{8}$

De la población mayor de 18 años en Sonora en 2014, 53.6\% son mujeres y $46.5 \%$ hombres. ${ }^{9}$ Tienen 43 años de edad en promedio en un rango de 18 a 91, con una desviación estándar de 16.2. En promedio, cuentan con 11.1 años de educación: primaria y secundaria completas y al menos dos años de preparatoria. Este promedio es mayor que el alcanzado a escala nacional (9.8) durante el mismo periodo.

Casi 60\% (59.4) vive con una pareja sentimental, ya sea casado o en unión libre, mientras que $20.2 \%$ es soltero, $12.6 \%$ separado o divorciado y $7.8 \%$ viudo.

Con el término de seguridad ciudadana, el INEGI se refiere a la seguridad o a la inseguridad de las personas para desempeñar sus labores cotidianas, como andar por la ciudad o por su colonia. También hace referencia a la confianza que se tiene para dejar la casa y partir con tranquilidad a realizar sus labores diarias (INEGI, 2014). La escala de satisfacción con la seguridad ciudadana $-y$ con algunos aspectos o dominios de la vida- que ofrece el BIARE, va de 0 a 10, donde 0 es totalmente insatisfecho y 10 totalmente satisfecho. Pero el propio INEGI brinda otra clasificación: considera muy satisfechas a las personas que contestaron 10 y 9 , satisfechas si contestaron 8 y 7 , insatisfechas 6 y 5 y muy insatisfechas $4,3,2,1$ y 0 .

7 A la fecha, la ENIGH 2016 se encuentra disponible; sin embargo, no se utilizó debido a que para este periodo no se incluyó el Módulo del BIARE.

8 Se agregan al análisis contextual datos de la Encuesta Nacional de Victimización y Percepción sobre Seguridad Pública (ENVIPE) de 2019 en Sonora. Cada caso está especificado en el texto o en la gráfica (INEGI, 2019b).

9 La Encuesta Intercensal 2015 del INEGI reportó para Sonora un porcentaje de 50.5\% de mujeres y 49.5\% de hombres (INEGI, 2019a). 
En Sonora, el promedio de satisfacción que expresan las personas acerca de su seguridad ciudadana es de 5.8 , que según la clasificación del INEGI puede considerarse insatisfechas. Como se observa en la figura 1, poco más de la mitad de la población (52.5\%) se encuentra insatisfecha o muy insatisfecha con su seguridad ciudadana. Y existe un porcentaje menor para la categoría de mayor satisfacción: $18.3 \%$.

Figura 1. Porcentaje de la población de Sonora según la satisfacción con la seguridad ciudadana

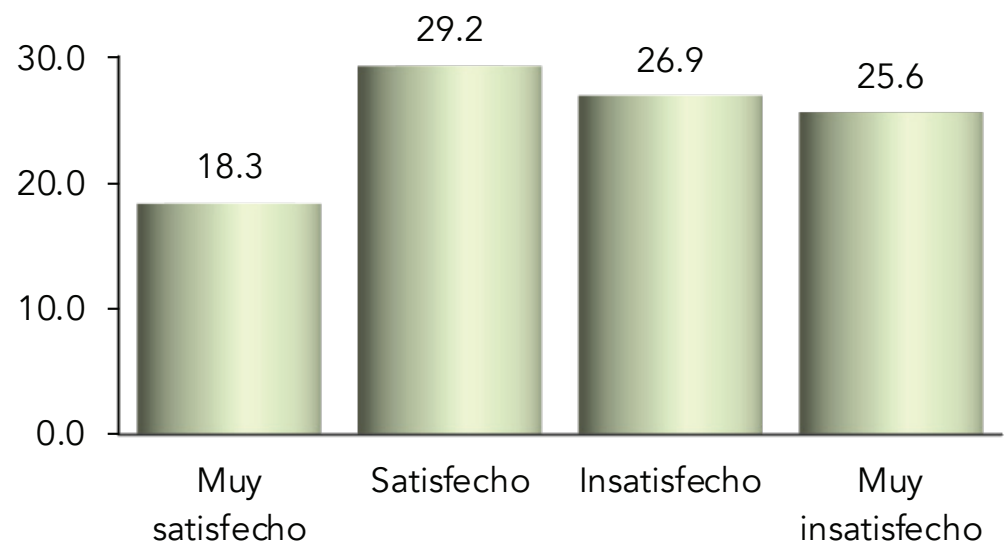

Fuente: elaboración propia con base en los datos del INEGI (2015b).

Según la ENVIPE, de la población total en el estado de Sonora en 2019, 68.3\% expresa una percepción de inseguridad que ha ido en aumento en los últimos años, pues en 2011 este porcentaje era de 46\% (véase figura 2).

Figura 2. Percepción de inseguridad en Sonora

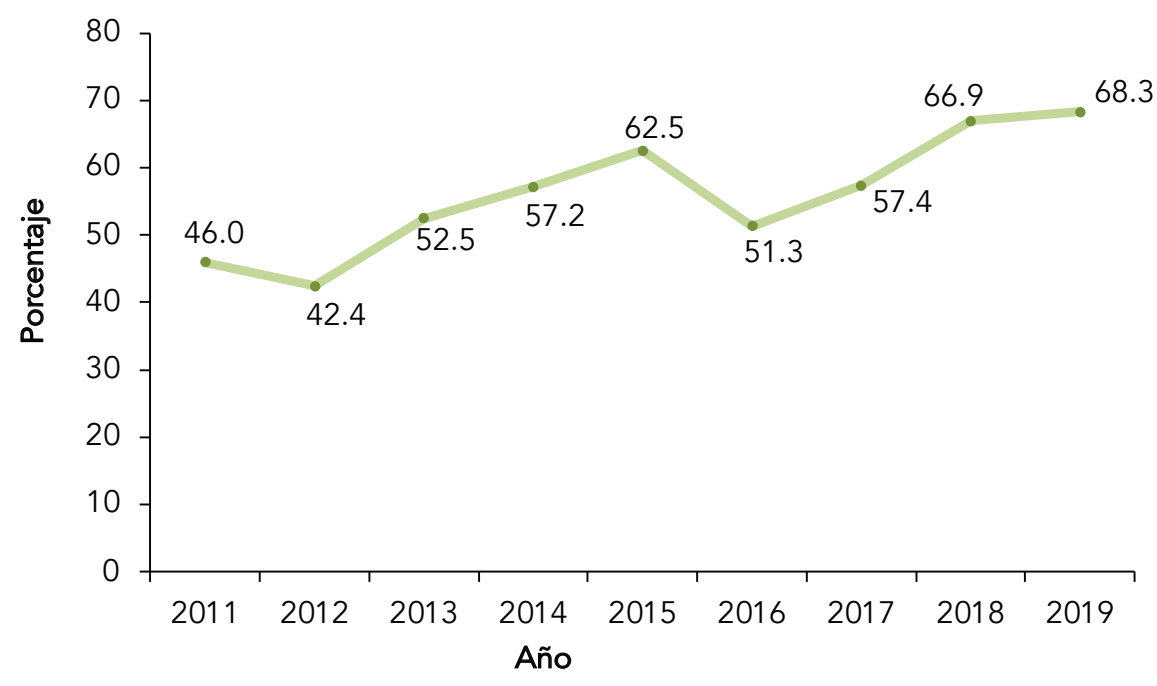

Fuente: elaboración propia con base en los datos del INEGI (2019b). 
El promedio de satisfacción que declara la población sonorense acerca de vivir en México, es 6.9 en la escala de 0 a 10. Casi $65 \%$ dice estar satisfecho o muy satisfecho de vivir en el país. En contraste, $22.1 \%$ dice estar insatisfecho y $12.9 \%$, muy insatisfecho (véase figura 3 ).

Figura 3. Porcentaje de la población de Sonora según satisfacción con su país

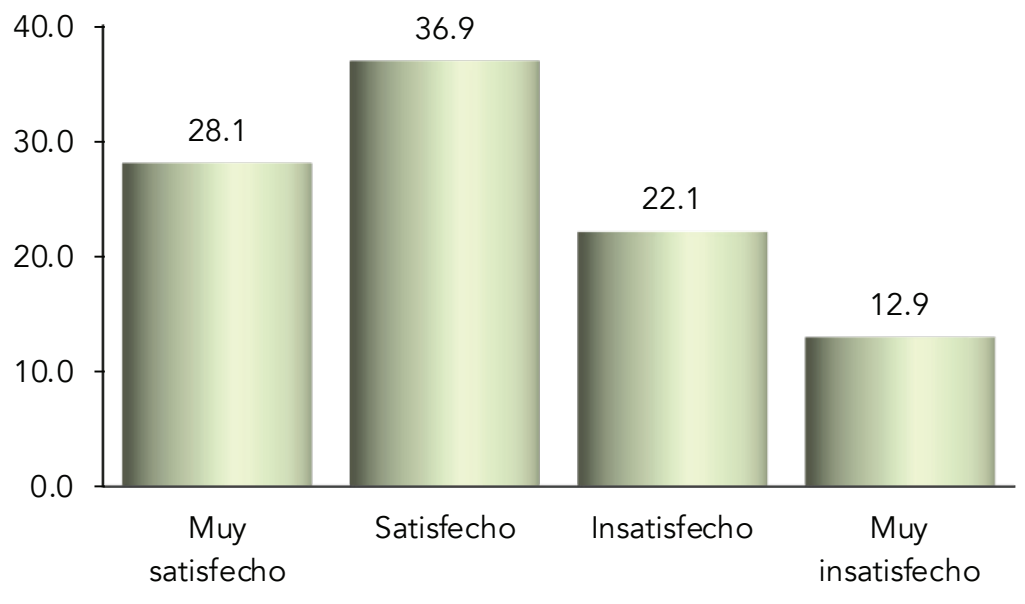

Fuente: elaboración propia con base en los datos del INEGI (2015b).

Sonora cuenta con 76 municipios. Los habitantes de la entidad expresan con un promedio de 7.6 la satisfacción de vivir en su ciudad. Como se observa en la figura 4, los muy satisfechos y los satisfechos suman $76.3 \%$ de la población, mientras que la categoría de menor satisfacción baja a 7.5\%.

Figura 4. Porcentaje de la población de Sonora según la satisfacción con su ciudad

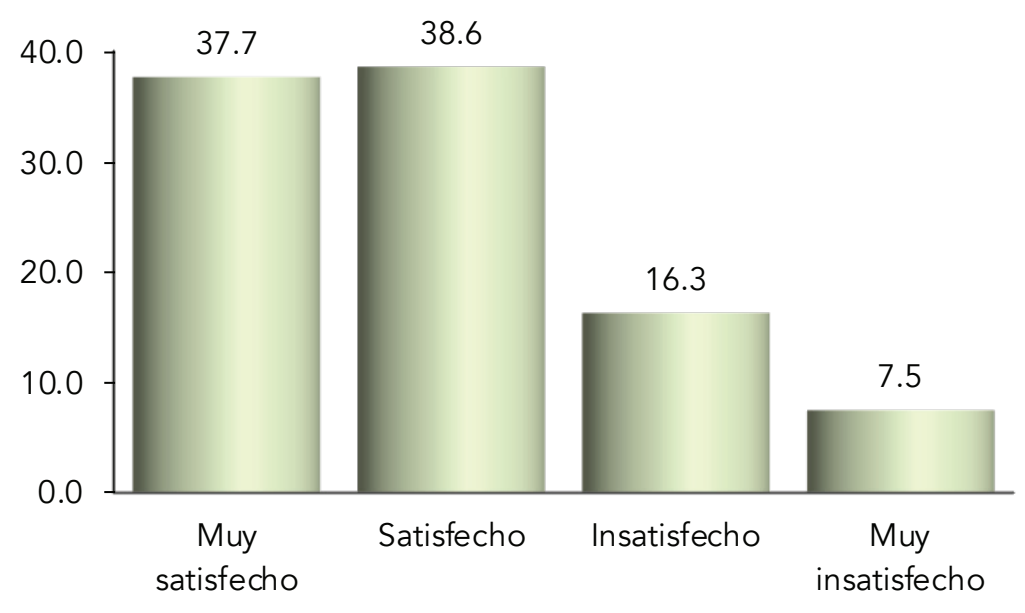

Fuente: elaboración propia con base en los datos del INEGI (2015b). 
Con respecto a 2019, la encuesta ENVIPE reporta que $64.2 \%$ de la población manifiesta una percepción de inseguridad en su municipio. Como se observa en la figura 5, este porcentaje aumentó 51.1\% de 2011 a 2019.

Figura 5. Percepción de inseguridad en el municipio

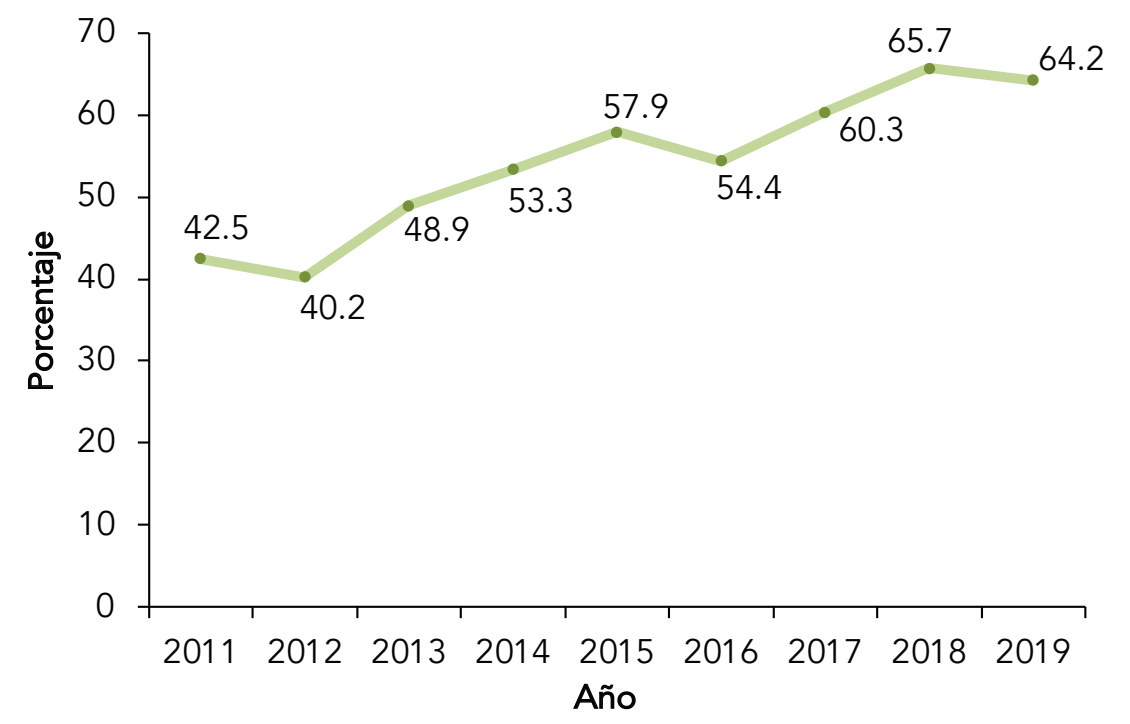

Fuente: elaboración propia con base en los datos del INEGI (2019b).

En lo que concierne al vecindario, la población de Sonora manifiesta un alto promedio de satisfacción, 8.0, que en la escala de 0 a 10 puede considerarse de satisfecha. Así, 49.7\% de la población en la entidad dice estar muy satisfecha con el vecindario donde vive, seguida de la que dijo estar satisfecha (31.7\%), mientras que se reducen las categorías de insatisfacción, pues juntas represen$\tan 18.6 \%$ (véase figura 6 ).

Figura 6. Porcentaje de la población de Sonora según la satisfacción con su vecindario

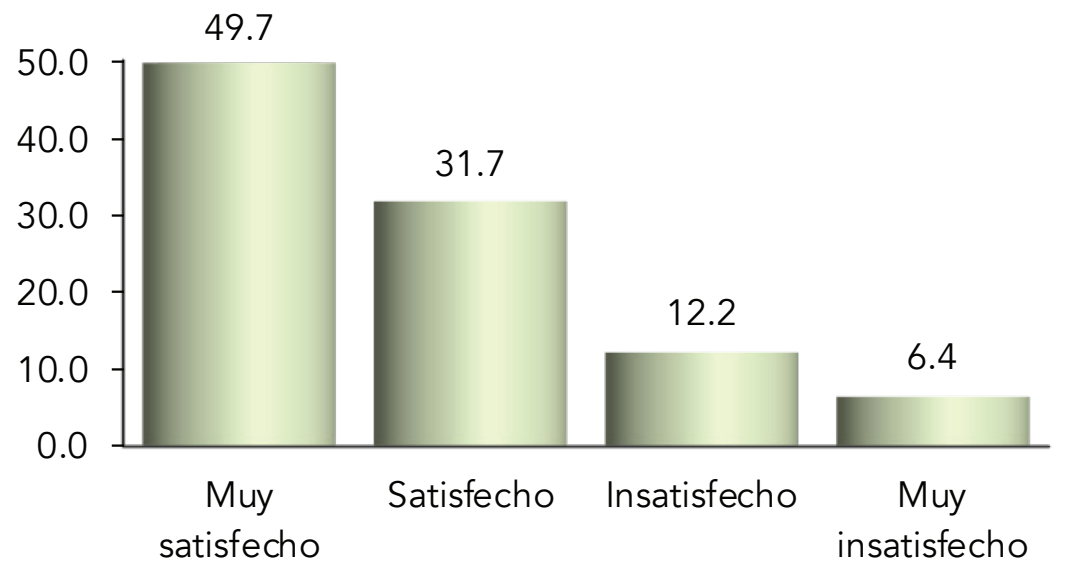

Fuente: elaboración propia con base en los datos del INEGI (2015b). 
Como se aprecia en la figura 7, la ENVIPE 2019 presenta la percepción de inseguridad que expresan los sonorenses sobre su colonia, registrando un progresivo aumento en los últimos años: $29.8 \%$ en 2011, 40.3\% en 2016 y $44.9 \%$ en 2019.

Figura 7. Percepción de la inseguridad en la colonia o localidad

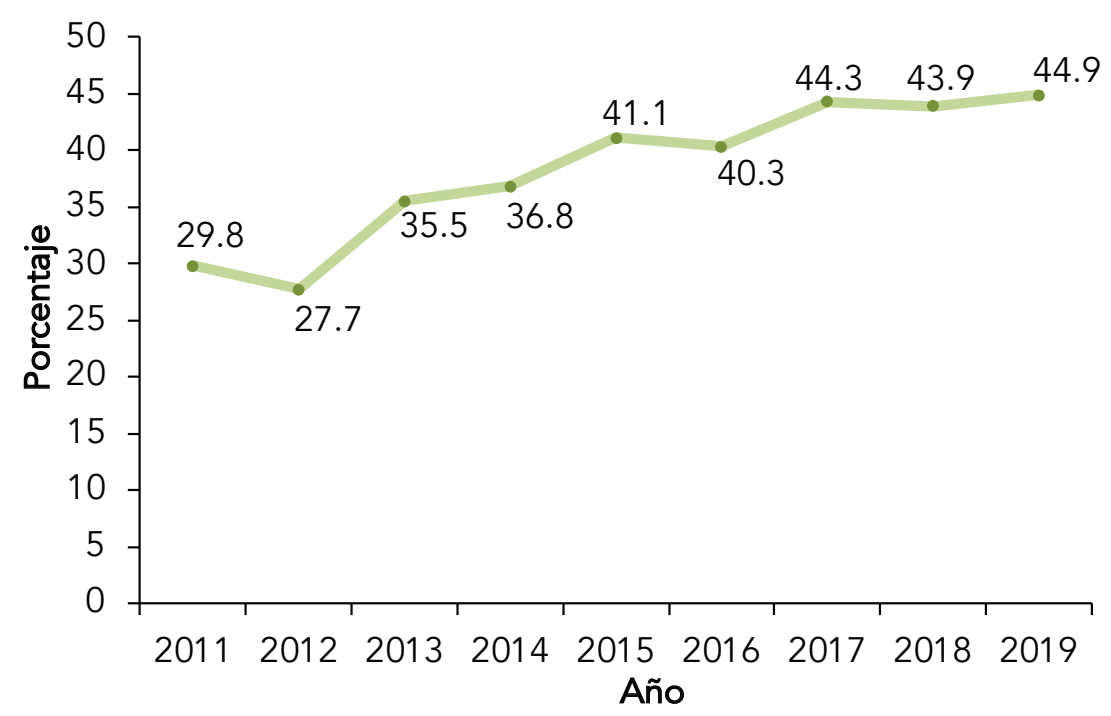

Fuente: elaboración propia con base en los datos del INEGI (2019b).

Por otra parte, $8.7 \%$ de la población de Sonora dijo haber sufrido algún tipo de agresión física o recibido alguna amenaza. ${ }^{10}$ Tomando en consideración este evento, existe una diferencia de un punto en el promedio de satisfacción con la seguridad ciudadana entre aquellas personas que expresan no haber sufrido ninguna agresión y las que manifiestan haberse enfrentado a esta situación: 5.9 y 4.9 , respectivamente (véase figura 8 ).

Para el caso de la ENVIPE, del total de los hogares de la entidad en 2018, $36.3 \%$ fue víctima de un delito. Al preguntárseles sobre las conductas delictivas o antisociales que se reportan con mayor frecuencia en los alrededores de su vivienda, $64 \%$ reportó el consumo de drogas, $45.5 \%$ la venta de drogas y $21.5 \%$ las riñas entre vecinos.

Por otra parte, $2.3 \%$ de la población de Sonora expresó pertenecer a una organización de vecinos. Se presentan diferencias en cuanto a la satisfacción con la seguridad ciudadana entre estas personas y las que no participan en este tipo de organización: 6.4 y $5.8 \%$, respectivamente.

De los habitantes de Sonora, 3.6\% manifestó que alguna de las personas con las que vive tiene problemas de drogadicción y al preguntárseles sobre su satisfacción ciudadana, expresan un promedio de 5.5, que es menor al 5.9 que presentan las personas que no tienen en su entorno esta problemática.

10 Durante los últimos 12 meses previos a la entrevista del BIARE. 
Figura 8. Promedio de satisfacción con la seguridad ciudadana según el sufrimiento de agresión física o amenaza

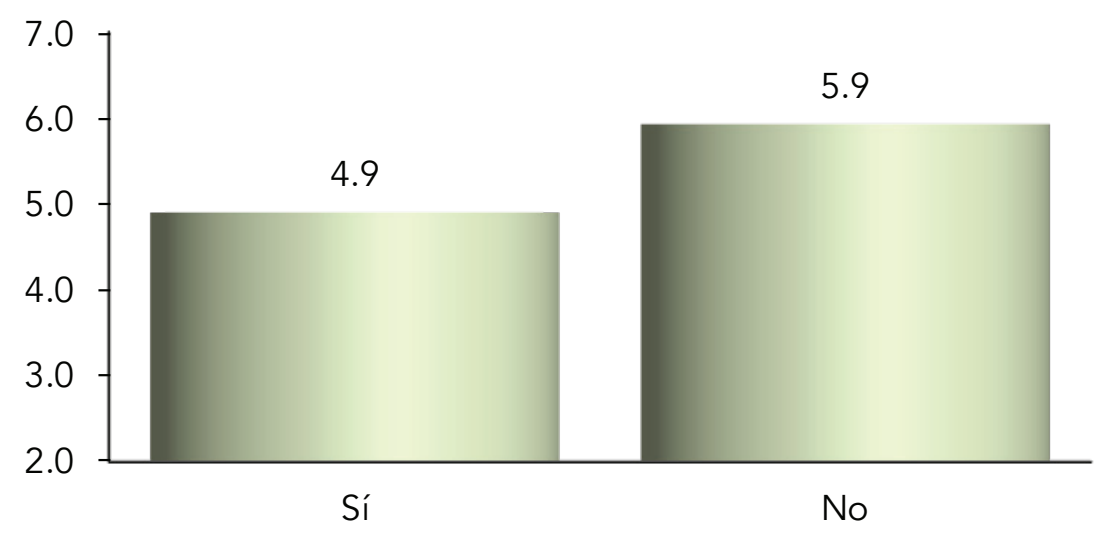

Sufrió alguna agresión física o recibió alguna amenaza

Fuente: elaboración propia con base en los datos del INEGI (2015b).

\section{Metodología}

Se ha empleado un modelo econométrico mediante el método logit dicotómico para presentar los determinantes de probabilidades sobre la satisfacción de la población sonorense con la seguridad ciudadana.

Lo anterior descansa sobre el concepto ampliado de seguridad ciudadana, que busca el bienestar de las personas y no sólo utilizar un modelo de seguridad punitivo. Siguiendo la literatura del tema, para construir el modelo se han seleccionado variables relacionadas con el entorno inmediato donde se desenvuelven las personas, así como variables de satisfacción de seguridad: vivir con una persona que tiene problemas de drogas, haber sufrido alguna agresión física o recibido alguna amenaza, participar en una asociación de vecinos y la satisfacción con la colonia, la ciudad y el país. Todos estos aspectos están relacionados con un enfoque de seguridad ciudadana sustentado en el desarrollo integral y en la dignidad humana.

La ENIGH recoge la opinión que las personas expresan sobre su seguridad ciudadana en la métrica del 0 al 10 -donde 0 es totalmente insatisfecho y 10 totalmente satisfecho-. Aunque la valoración está en un parámetro numérico, en su respuesta las personas atribuyen una elección cualitativa acerca de la satisfacción, no un promedio. En otras palabras, la satisfacción con la seguridad ciudadana responde a cuestiones de percepción y se trata como variable nominal categórica y no como variable continua. ${ }^{11}$ La selección del método

11 Es decir, que hace referencia a valores cualitativos y no a una variable continua que puede tomar valores sin ninguna limitación entre un valor y otro. 
logit dicotómico tiene como fundamento el carácter cualitativo de la variable explicada, o sea, la seguridad ciudadana.

La ENIGH ha transformado la variable sobre seguridad ciudadana en una variable nominal categórica, codificándola en cuatro criterios (véase tabla 1).

Tabla 1. Métrica sobre seguridad ciudadana del INEGI

\begin{tabular}{|c|c|c|}
\hline \multirow{2}{*}{$\begin{array}{c}\text { Valoración en cuestionario } \\
\text { (métrica del 0 al 10) }\end{array}$} & \multicolumn{2}{|c|}{ Codificación nueva } \\
\cline { 2 - 3 } & Categoría & Valor \\
\hline 9 ○ 10 & Muy satisfecho & 4 \\
\hline $8 \circ 7$ & Satisfecho & 3 \\
\hline $6 \circ 5$ & Insatisfecho & 2 \\
\hline 4 o menos & Muy insatisfecho & 1 \\
\hline
\end{tabular}

Fuente: elaboración propia con base en los datos del INEGI (2015b).

El modelo logit dicotómico evalúa criterios cualitativos y, en su forma de elección discreta, la estimación de la variable dependiente se encuentra limitada y comprendida por los valores 0 y $1 .{ }^{12}$ De tal forma, en el presente artículo se lleva a cabo una recodificación de la satisfacción con la seguridad ciudadana, según se observa en la tabla 2.

Tabla 2. Recodificación de la métrica sobre seguridad ciudadana

\begin{tabular}{|c|c|c|c|c|}
\hline \multirow{2}{*}{$\begin{array}{c}\text { Valoración } \\
\text { en el cuestionario del INEGI } \\
\text { (métrica del } 0 \text { al 10) }\end{array}$} & \multicolumn{2}{|c|}{$\begin{array}{l}\text { Recodificación } \\
\text { del INEGI }\end{array}$} & \multicolumn{2}{|c|}{ Recodificación propia } \\
\hline & Categoría & Valor & Categoría & Valor \\
\hline $9 \circ 10$ & Muy satisfecho & 4 & \multirow{2}{*}{ Satisfecho } & \multirow{2}{*}{1} \\
\hline $8 \circ 7$ & Satisfecho & 3 & & \\
\hline $6 \circ 5$ & Insatisfecho & 2 & \multirow{2}{*}{ Insatisfecho } & \multirow{2}{*}{0} \\
\hline 4 o menos & Muy insatisfecho & 1 & & \\
\hline
\end{tabular}

Fuente: elaboración propia.

El modelo logit seleccionado relaciona la variable endógena o dependiente con las variables explicativas a través de una función de distribución. Este método se interpreta en términos probabilísticos, ya que permite tener estimaciones de la probabilidad de un evento, es decir, mide la probabilidad de que ocurra un acontecimiento (Gujarati y Porter, 2010). En este caso, ofrece la probabilidad de que un individuo se encuentre satisfecho (1) o insatisfecho $(0)$ con su seguridad ciudadana en relación con la serie de criterios que se seleccionaron.

12 El valor 1 se refiere a la probabilidad de que un sujeto elija o se encuentre en una categoría. 
Se presenta a continuación la propuesta econométrica que evalúa la probabilidad de que una persona valore su satisfacción con la seguridad ciudadana que toma el papel de variable dependiente - en satisfecha o insatisfecha como una función de un conjunto de valores, definida a través de características de las variables explicativas o independientes: ${ }^{13}$

Probabilidad (ds_sc) $=\alpha+\beta_{1}$ dagre_fisica $+\beta_{2}$ dperten_5 $+\beta_{3}$ dpadece_3 $+\beta_{4}$
s_ve $+\beta_{5} s \_c+\beta_{6} s \_p+\beta_{7}$ dsexo $+\beta_{8}$ dconyug_edo $+u$

La tabla 3 presenta cada una de las variables utilizadas en la estimación econométrica que han sido construidas por los indicadores o temas rescatados de la ENIGH, de los cuales se muestra la definición o pregunta textual (según sea el caso) incluida en el cuestionario.

Tabla 3. Definición de variables para la estimación econométrica logit

\begin{tabular}{|c|c|c|}
\hline Variable & Indicador o tema & $\begin{array}{c}\text { Pregunta textual en cuestionario } \\
\text { /definición }\end{array}$ \\
\hline ds_sc & $\begin{array}{l}\text { Satisfacción con la seguridad } \\
\text { ciudadana. }\end{array}$ & $\begin{array}{l}\text { ¿Qué tan satisfecho está } \\
\text { con su seguridad ciudadana? }\end{array}$ \\
\hline dagre_física & $\begin{array}{l}\text { El integrante del hogar sufrió } \\
\text { alguna agresión física } \\
\text { o recibió alguna amenaza. }\end{array}$ & $\begin{array}{c}\text { Durante los últimos } 12 \text { meses, } \\
\text { ¿usted sufrió o fue objeto de una } \\
\text { agresión física o de una amenaza? }\end{array}$ \\
\hline dperten_5 & $\begin{array}{c}\text { El integrante pertenece } \\
\text { a una organización de vecinos. }\end{array}$ & $\begin{array}{l}\text { ¿Pertenece usted a una } \\
\text { organización de vecinos? }\end{array}$ \\
\hline dpadece_3 & $\begin{array}{l}\text { Alguna persona del hogar } \\
\text { sufre drogadicción. }\end{array}$ & $\begin{array}{c}\text { Alguna de las personas } \\
\text { con las que usted vive, ¿padece } \\
\text { de drogadicción? }\end{array}$ \\
\hline s_ve & Satisfacción con el vecindario. & $\begin{array}{l}\text { ¿Qué tan satisfecho está } \\
\text { con su vecindario? }\end{array}$ \\
\hline s_c & Satisfacción con la ciudad. & $\begin{array}{l}\text { ¿Qué tan satisfecho está } \\
\text { con su ciudad? }\end{array}$ \\
\hline$s \_p$ & Satisfacción con el país. & $\begin{array}{l}\text { ¿Qué tan satisfecho está } \\
\text { con su país? }\end{array}$ \\
\hline dsexo & Sexo & $\begin{array}{l}\text { Distinción biológica que clasifica a } \\
\text { las personas en hombres o mujeres }\end{array}$ \\
\hline dconyug_edo & Estado civil & $\begin{array}{c}\text { Estado conyugal del integrante } \\
\text { del hogar. }\end{array}$ \\
\hline
\end{tabular}

Fuente: elaboración propia con base en los datos del INEGI (2015b).

13 Se agrega además el error aleatorio "u" el cual se asume que sigue una distribución logística. 
La tabla 4 ofrece la escala o valor asignado en la ecuación logística a cada una de las variables, así como la definición de dicha escala.

Tabla 4. Transformación de variables para la estimación econométrica logit

\begin{tabular}{|c|c|c|}
\hline Variable & Escala o valor & Definición de escala/valor \\
\hline ds_sc & $0-1$ & $\begin{array}{c}\text { Variable dummy: } 1 \text { si contestó } 7,8,9 \text { o 10; } \\
\text { y } 0 \text { si contestó del } 0 \text { al } 6 .\end{array}$ \\
\hline agre_física & $0-1$ & $\begin{array}{l}\text { Variable dummy: } 1 \text { si sufrió alguna agresión física } \\
\text { o recibió alguna amenaza; y } 0 \text { en caso contrario. }\end{array}$ \\
\hline dperten_5 & $0-1$ & $\begin{array}{l}\text { Variable dummy: } 1 \text { si pertenece a alguna } \\
\text { organización de vecinos; y } 0 \text { en caso contrario. }\end{array}$ \\
\hline dpadece_3 & $0-1$ & $\begin{array}{c}\text { Variable dummy: } 1 \text { si alguna de las personas } \\
\text { con las que vive padece de drogadicción; } \\
\text { y } 0 \text { en caso contrario. }\end{array}$ \\
\hline s_ve & Del 0 al 10 & $\begin{array}{l}0=\text { totalmente insatisfecho; } \\
\text { y } 10 \text { =totalmente satisfecho. }\end{array}$ \\
\hline S_c & Del 0 al 10 & $\begin{array}{l}0=\text { totalmente insatisfecho; } \\
\text { y } 10 \text { =totalmente satisfecho. }\end{array}$ \\
\hline s_p & Del 0 al 10 & $\begin{array}{l}0=\text { totalmente insatisfecho; } \\
\text { y } 10=\text { totalmente satisfecho. }\end{array}$ \\
\hline dsexo & $0-1$ & Variable dummy: 1 si es hombre; y 0 si es mujer. \\
\hline dconyug_edo & $0-1$ & $\begin{array}{l}\text { Variable dummy: } 1 \text { si es casado(a) } \\
\text { o vive en unión libre; y } 0 \text { si es soltero(a), } \\
\text { divorciado(a), separado(a) o viudo(a). }\end{array}$ \\
\hline
\end{tabular}

Fuente: elaboración propia.

Puesto que el módulo BIARE es una encuesta muestral, se utilizó la variable factor de expansión para ponderar la muestra, la cual el INEGI calcula y presenta dentro de la encuesta, y se define como el inverso de la probabilidad de selección de un individuo en la muestra (INEGI, 2014). ${ }^{14}$

Antes de presentar los resultados de la regresión logit, es necesario dejar evidencia sobre la consideración de variables que han quedado fuera del estudio. De modo específico, en un primer momento se llevó a cabo la inclusión en el modelo de cuatro variables más, las cuales, a pesar de contar con sustento teórico para su incorporación, no resultaron tener significancia particular en la determinación de probabilidades, además de que no contribuyeron a la significancia conjunta. Por lo tanto, se han excluido del modelo.

Las preguntas textuales del cuestionario en relación con las cuatro variables son: a) Durante los últimos 12 meses, ¿alguna persona muy cercana e importan-

14 Según el INEGI, este factor de expansión se utiliza para compensar la tasa de no respuesta que de forma específica afectó la fase de entrevista BIARE, y se traduce como el número de individuos fuera de la muestra con características similares al que sí está en la muestra y que, por lo tanto, éste último representa. 
te para usted fue víctima de una agresión física o verbal? b) Durante los últimos 12 meses, ¿alguna persona muy cercana e importante para usted se extravió, desapareció o fue detenida por autoridades u otras personas? c) ¿Alguna de las personas con las que usted vive, padece de tabaquismo? d) ¿Alguna de las personas con las que usted vive, padece de alcoholismo?

Siguiendo a Ruíz y Murraín (2012), quienes hablan de particularidades culturales específicas de un lugar, ${ }^{15}$ la no significancia de estas variables contribuye al análisis de la seguridad ciudadana porque otorga herramientas para delimitar el análisis regional y porque brinda fundamentos para futuras investigaciones. En particular, las variables c) y d), sobre tabaquismo y alcoholismo, podrían estar resaltando la magnitud de la problemática de las drogas (que sí resultó tener significancia) y sus efectos en el contexto estatal.

\section{Resultados de la percepción de seguridad ciudadana en Sonora}

Como se observa en la tabla 5, el indicador $\mathrm{Chi}^{2}$ es significativo, ${ }^{16}$ el cual mide la bondad de ajuste del modelo logístico. Se brinda así la seguridad de que la propuesta econométrica se ajusta de manera apropiada a los datos y que existe relación entre las variables explicativas y la seguridad ciudadana. Por lo tanto, las variables seleccionadas sirven de forma adecuada para la estimación de probabilidades.

Tabla 5. Resultados de la regresión logit de la razón de probabilidades sobre la seguridad ciudadana en Sonora

\begin{tabular}{|c|c|c|c|}
\hline Variable & \multicolumn{3}{|c|}{ Razón de probabilidades } \\
\hline dagre_fisica & 0.9069666 & $(0.0052196)$ & $*$ \\
\hline dperten_5 & 1.854663 & $(0.019533)$ & $*$ \\
\hline dpadece_3 & 0.9219839 & $(0.007903)$ & $*$ \\
\hline s_ve & 1.135149 & $(0.0009868)$ & $*$ \\
\hline s_c & 1.209163 & $(0.0012345)$ & $*$ \\
\hline s_P & 1.196551 & $(0.0009548)$ & $*$ \\
\hline dsexo & 0.9888302 & $(0.0030975)$ & $*$ \\
\hline dconyug_edo & 0.8623834 & $(0.0027369)$ & $*$ \\
\hline Pseudo (R) & & 0.1132 & \\
\hline Número de observaciones & \multicolumn{3}{|c}{1,260} \\
\hline Prob $>$ chi ${ }^{2}$ & \multicolumn{3}{|c}{0.0000} \\
\hline
\end{tabular}

* Significativo a $1 \%$

Fuente: elaboración propia.

15 En su estudio dice "de una ciudad a otra".

16 Este estadístico sigue una distribución $\mathrm{Chi}^{2}$ con ocho grados de libertad, es decir, igual al número de parámetros estimados. 
Se reporta un pseudo $\mathrm{R}^{2}$ de 0.1132 que, aunque en la actualidad continúa en un debate acerca de su interpretación (Rodríguez y Cáceres, 2007), es el único indicador aproximado al $\mathrm{R}^{2}$ en regresiones lineales que hace referencia a la explicación de la variación total del modelo. El valor de este indicador se considera un buen resultado en investigaciones de las ciencias sociales, por lo que se puede decir que existe una buena explicación mediante las variables independientes para la estimación de probabilidades en la seguridad ciudadana.

Cada una de las variables seleccionadas como explicativas muestra significancia particular, lo cual establece relaciones causales individuales, es decir, la determinación de probabilidades para la ecuación de seguridad ciudadana. De este modo se concluye que la propuesta econométrica mediante el método logit para la determinación de probabilidades en la seguridad ciudadana en Sonora, es adecuada. Según los objetivos propuestos, el modelo tiene una buena capacidad predictiva y obtiene parámetros significativos en términos estadísticos.

Con el fin de ofrecer una interpretación más sencilla en la determinación de probabilidades, para el análisis y la interpretación de coeficientes se utiliza el antilogaritmo o razón de probabilidades. ${ }^{17}$ Se interpreta como el cociente entre la probabilidad de que se elija una opción frente a la probabilidad de que no se elija, es decir, el número de veces que es más probable que se elija una opción frente a que no se elija.

Para cada una de las variables que se incluyeron en el modelo logit, los resultados tienen un nivel de significancia de $1 \%$, o sea, un nivel de confianza de $99 \%$, en una lectura particular donde se mantiene constante el resto de las variables del modelo.

El modelo arroja que los sonorenses que declararon haber sufrido una agresión física o recibido una amenaza, son $10 \%$ menos probables de estar satisfechos con su seguridad ciudadana que los que no han pasado por esta circunstancia. Este dato es de suma importancia, porque la violencia familiar está aumentando cada vez más y proporciona la magnitud del problema. De acuerdo con la información del Secretariado Ejecutivo del Sistema Nacional de Seguridad Pública, en los primeros siete meses de 2019, las autoridades de Sonora atendieron 40778 llamadas; esto es, alrededor de 5826 casos por mes y 194 diarios por violencia familiar, cifra que ubica a Sonora en la tercera posición nacional.

Los ciudadanos que dijeron pertenecer a una organización de vecinos, son $85 \%$ más probables a estar satisfechos con su seguridad ciudadana que los que no pertenecen a una organización de este tipo. Esta variable muestra que el sentido de pertenencia establece lazos comunitarios en el vecindario (Sutton y Godinez, 2017), lo cual genera buena convivencia y ambientes pacíficos en favor de la seguridad ciudadana.

Aquellos sonorenses que manifestaron vivir con alguna persona que sufre drogadicción, son $8 \%$ menos probables a estar satisfechos con su seguridad ciu-

17 Los coeficientes o parámetros estimados en los modelos de regresión logística no son equivalentes a la variación en la probabilidad, ya que se considera que existe una relación no lineal entre las variables explicativas y las probabilidades. El antilogaritmo o razón de probabilidades es la combinación lineal exponenciada (rescatada de la razón logarítmica de las probabilidades) de las variables explicativas y los coeficientes estimados. 
dadana que aquellos que en cuyo hogar no se presenta esta problemática. Lo anterior deja de manifiesto que el problema de las drogas se expresa en detrimento de la seguridad en la vida de las personas (Insulza, 2014), la cual afecta no sólo al individuo sino también a la familia y a la comunidad.

Haber sufrido una agresión física o recibido una amenaza o convivir en el hogar con alguna persona que tenga un problema de drogadicción son factores de riesgo asociados con la violencia y la criminalidad. Las agresiones físicas o amenazas en el hogar o en el entorno se traducen en hechos violentos y delictivos. Además, una persona que tiene un problema de adicción tiende a robar o a cometer algún otro tipo de delito, con tal de obtener dinero para mantener su adicción y, en casos extremos, a atentar contra su vida o la de otras personas. Ambas situaciones afectan de manera negativa la seguridad ciudadana. Por el contrario, pertenecer a una organización ciudadana (por ejemplo, un comité de vecinos) actúa como factor de contención de la violencia y de la inseguridad, pues dicha participación fortalece la seguridad y la percepción de ésta.

Después del hogar, el vecindario es el entorno más próximo que debería brindar seguridad a las personas. Se observa que el aumento de una unidad en la valoración de la satisfacción que tienen las personas con su vecindario, ${ }^{18}$ aumenta $13 \%$ las probabilidades de estar satisfechas con su seguridad ciudadana. Mirar el territorio en sus dimensiones de sociedad, lleva a descubrir que tiene una "gran significación en materia de seguridad ciudadana" (Escobar et al., 2005, p. 32). El territorio es una zona con características específicas -capaces de activar la participación ciudadana- y propicia la planificación de la seguridad. Lo anterior descansa sobre un capital social que se puede activar a través de rutinas de confianza entre los tres agentes involucrados: la autoridad política, las policías y los ciudadanos, todo dentro de un concepto más amplio de desarrollo (Escobar et al., 2005).

En cambio, si la colonia presenta factores de riesgo como, por ejemplo, el consumo de alcohol en la vía pública, robo y asaltos frecuentes en las calles cercanas al hogar, entre otros, la seguridad ciudadana se verá mermada. Ante esta situación problemática, identificar los lugares cuyos índices de delito son altos da la oportunidad de llevar a cabo planes de prevención y actuación focalizados en dichas zonas. En este contexto, el espacio inmediato, como la colonia, se convierte en un aspecto significativo de análisis. Aquí es necesaria la responsabilidad colectiva mediante acciones de prevención, vigilancia y cooperación con las autoridades (Escobar et al., 2005), con el fin de diagnosticar y diseñar de forma precisa estrategias particulares para que las intervenciones influyan sobre el entorno y disminuyan las oportunidades de delinquir, como controlar la venta de alcohol, mejorar los espacios públicos y establecer estrategias policiales focalizadas en ciertos territorios (CAF, 2014).

Los mismos factores de riesgo se pueden presentar también a escala nacional y afectar la seguridad ciudadana. Según los resultados, la población de Sonora manifestó que por cada punto que aumenta la satisfacción de vivir en su ciudad, aumentan en $20 \%$ las probabilidades de estar satisfecho con la seguridad ciudadana. Para los sonorenses, conforme aumenta una unidad la satisfacción

18 Se recuerda que la escala de valor va de 0 a 10. 
que se tiene de vivir en el país, la probabilidad de estar satisfecho con la seguridad ciudadana aumenta 19\%. La satisfacción en el entorno inmediato, ampliada a la ciudad y al país, se une a la percepción de certeza en varios aspectos de la vida de las personas, como la libertad, por ejemplo (Gudiño, 2001). Aquí se abre el enfoque a un contexto más amplio, donde, además del entorno inmediato, las acciones de combate al crimen involucran las dimensiones de la familia, la escuela, la comunidad, la infraestructura urbana, las regulaciones económicas, la justicia y las cárceles, por mencionar algunas (CAF, 2014). El trabajo para la seguridad en esas dimensiones es más extenso y responde a acciones de mediano y largo plazos. La promoción de ambientes familiares no conflictivos, el fortalecimiento de la nutrición y la estimulación temprana en niños han demostrado tener consecuencias positivas en la propensión criminal, pues han logrado la reducción en la incidencia del delito. Lo mismo ha sucedido con las intervenciones en el ámbito escolar en niños y adolescentes para reducir la exposición al crimen de los jóvenes (CAF, 2014).

Se agregaron a la ecuación sobre seguridad ciudadana en Sonora dos variables de control: el sexo y el estado conyugal. En relación con la primera, se observa que los hombres tienen $2 \%$ menos probabilidades de estar satisfechos con su seguridad ciudadana que las mujeres. Se puede decir que aquellas personas que viven una relación de pareja ya sea de matrimonio o de unión libre, tienen $14 \%$ menos probabilidades de estar satisfechas con su seguridad ciudadana en relación con las que no tienen dicho vínculo, ya sea porque son viudas, divorciadas o separadas.

\section{Conclusiones}

Para los sonorenses, la inseguridad pública representa una de las principales preocupaciones y problemáticas sociales (INEGI, 2019b). La evidencia dice que la violencia se ha incrementado de manera exponencial en los últimos años en México y en Sonora. La solución al problema no es incrementar el número de efectivos de las fuerzas públicas y dotarlos con mayor y mejor armamento, enfoque basado en la fuerza y no en la inteligencia, en el que se analizan los efectos y no las causas u orígenes de unos fenómenos tan complejos como la violencia y la inseguridad.

Los enfoques convencionales orientados al control y a la represión, cuya perspectiva se basa en "el modelo policía-justicia-prisión” (Arriagada y Godoy, 2000, p. 118), han demostrado limitaciones para combatir la violencia, pues la tasa de homicidios ha crecido en la región. Los resultados insuficientes sobre los delitos, la criminalidad y la violencia, orientan la investigación de esos fenómenos hacia propuestas que busquen no sólo castigar o reprimir, sino también influir en el entorno social y familiar de los individuos. Se requieren enfoques integrales que interpreten la violencia como un fenómeno multidimensional, en el cuales las medidas preventivas cobren importancia y las estrategias de combate procuren incidir en lo individual, familiar, social y cultural (Arriagada y Godoy, 2000). 
La investigación propone una visión de seguridad que se centre en el ciudadano y en sus derechos humanos, "porque la seguridad es un bien que apunta a la calidad integral de vida de los ciudadanos" (Escobar et al., 2005, p. 10). Se ha subrayado la necesidad de analizar la seguridad desde una óptica que observe su carácter multidimensional, para identificar los factores objetivos y de percepción que detonan la seguridad ciudadana de los individuos. Se argumenta que es de vital importancia identificar los factores precursores de riesgo y los detonadores de violencia que se expresan en ausencia de los derechos económicos, sociales y culturales.

El estudio se ha centrado en el estado de Sonora para dar una visión de la seguridad ciudadana específica para el análisis regional, lo cual, además de abonar información a la literatura sobre el tema, puede utilizarse de base o referencia para futuras investigaciones. El artículo pretende enriquecer, mediante una visión integral, el conocimiento sobre la seguridad ciudadana en Sonora.

Los resultados de la investigación sugieren que toda política de seguridad ciudadana requiere para su cabal funcionamiento un contexto que la ubique dentro de una visión más amplia de desarrollo social e integral. Por lo tanto, se han resaltado tanto dimensiones que aluden al comportamiento del individuo como aquellas que buscan explicar la aparición y la consolidación de los procesos a partir del territorio y del entorno, como componentes importantes en la determinación de la satisfacción con la seguridad ciudadana.

En suma, la investigación ofrece varias contribuciones a la literatura sobre la seguridad. En primer lugar, sugiere que los estudios sobre el tema deben abordarse con una perspectiva que procure incluir los aspectos ligados al bienestar de las personas, que observe la violencia como un fenómeno multifactorial. En segundo lugar, se presentan los determinantes o causales que inciden sobre la seguridad ciudadana. En tercer lugar, debido a la metodología basada en un modelo econométrico, el trabajo presenta la contribución que cada uno de estos determinantes hace al análisis de la seguridad ciudadana. Debido a que es un estudio enfocado en Sonora, clarifica los posibles procesos de territorialización y sirve de referente comparativo para futuras investigaciones; por consiguiente, coadyuva al análisis regional de la seguridad ciudadana.

El cambio de modelo exige a su vez un cambio institucional a fondo entre los diferentes organismos responsables de enfrentar la inseguridad en los tres niveles de gobierno, es decir, en la dimensión gubernamental. El trabajo unidireccional de las dependencias sólo trae consigo el despilfarro de recursos y el cumplimiento parcial de las metas, en el mejor de los casos. Las instituciones actúan de manera independiente y sin coordinación, y la consecuencia es un efecto nulo en la reducción de los indicadores de violencia. El tránsito de modelo exige el trabajo coordinado y planeado de forma interinstitucional para diseñar políticas públicas que vayan al origen del fenómeno, de prevención y de atención a la violencia.

Tiene mucha importancia la acción tanto del gobierno como de la ciudadanía para lograr los fines propuestos en materia de seguridad ciudadana, la cual "ha pasado a formar parte de los bienes y aspiraciones más preciados por las personas” (San Martín, 2012, p. 73); también la participación del Estado 
como generador de políticas sociales mediante las instituciones de gobierno con compromiso social y respeto a los derechos humanos, pues la definición de las acciones corresponde al gobierno como entidad responsable y encargada del diagnóstico y del uso de recursos para proponer soluciones a la inseguridad a corto, mediano y largo plazos (Escobar et al., 2005). Se ha puesto de manifiesto que la seguridad, además de ser el derecho más básico del ciudadano, es una “obligación fundamental del Estado” (Muggah, 2017, p. 292).

Todas las acciones para la seguridad y la prevención del delito de todos los actores involucrados, en especial las del gobierno, debido a su responsabilidad y a su obligación social, abonarán al progreso de la región si se logra reducir las altas tasas de inseguridad y violencia que se experimentan en la actualidad (CAF, 2014, p. 18).

\section{Referencias}

Aldana, S., y Ramírez, G. (2012). Seguridad ciudadana: viejos problemas, nuevas miradas. En A. Mockus, H. Murraín y M. Villa (coords.), Antípodas de la violencia. Desafíos de cultura ciudadana para la crisis de (in)seguridad en América Latina (pp. 87-114). Washington, D. C.: Banco Interamericano de Desarrollo.

Arriagada, I., y Godoy, L. (2000). Prevenir o reprimir: falso dilema de la seguridad ciudadana. Revista de la CEPAL (70), 107-131.

Brantingham, P. J., y Brantingham, P. L. (1984). Patterns in Crime. Nueva York: Macmillan.

Brantingham, P. J., y Brantingham, P. L. (1993). Nodes, paths and edges: considerations on the complexity of crime and the physical environment. Journal of Environmental Psychology (13), 3-28. doi: 10.1016/S0272-4944(05)802129

CAF-Banco de Desarrollo de América Latina. (2014). Por una América Latina más segura: una nueva perspectiva para prevenir y controlar el delito. Bogotá: Panamericana Formas e Impresos.

Clarke, R., y Cornish, D. (1985). Modeling offenders' decisions: a framework for research and policy. Crime and Justice: An Annual Review of Research (6), 147-185.

Cohen, L., y Felson, M. (1979). On estimating the social costs of national economic policy: a critical examination of the Brenner study. Social Indicators Research (6), 251-259. doi: 10.1007/BF00343977

Dammert, L. (2005). De la seguridad pública a la seguridad ciudadana. Chile: Jefatura de División de Seguridad Ciudadana.

Dammert, L., Mujica, J., y Zeballos, N. (2017). Seguridad ciudadana. balance de investigación en políticas públicas 2011-2016 y agenda de investigación 2017-2021. Consorcio de Investigación Económica y Social (CIES) (54), 62108.

Escobar, G. (2012). Using social disorganization theory to understand the spatial distribution of homicides in Bogota, Colombia. Revista INVI, 27 (74), 21-85. doi: 10.4067/S0718-83582012000100002 
Escobar, S., Muniz, J., Sanseviero, R., Saín, M., y Zacchi, J. (2005). La seguridad ciudadana como política de Estado. Un marco conceptual para la acción de las fuerzas progresistas del Cono Sur. Santiago de Chile: Fundación Friedrich Ebert.

Flores, I., y Phillips, M. (2021). The perfect storm. An analysis of the processes that increase lethal violence in Mexico after 2006. Trends Organ Crime. doi: 10.1007/s12117-021-09410-5

Frühling, H. (2003). Policía comunitaria y reforma policial en América Latina ¿Cúal es el impacto? Santiago, Chile: Centro de Estudios en Seguridad Ciudadana.

García, G. D., y Quintana, M. R. (2015). La participación ciudadana en el nuevo sistema de seguridad. El caso de la provincia de Chaco. En Angarita Cañas (comp.), Drogas, policías y delincuencias. Otras miradas a la seguridad ciudadana en América Latina (pp. 51-64). Buenos Aires: CLACSO.

Garmendia Lorena, F. (2011). La violencia en América Latina. An Fac med., 72(4), 269-276.

González, F., Macedo, A., y Tinoco, A. (2014). Notas metodológicas para la construcción del observatorio de seguridad ciudadana en el Estado de México. En J. Estrada (coord.), Seguridad ciudadana: Visiones compartidas (pp. 229-253). Toluca: Géminis Editores e Impresores.

González Placencia, L. (1998). Inseguridad subjetiva y experiencias con el delito: actitudes respecto a la seguridad en Ciudad de México. Serie Documentos de Trabajo No.21. México: Fundación Rafael Preciado.

Gudiño Galindo, J. J. (2001). De seguridad pública a seguridad ciudadana. Este País (127), 42-51.

Gujarati, D., y Porter, D. (2010). Econometría. México: McGraw-Hill e Interamericana Editores.

Instituto Nacional de Estadística y Geografía (INEGI). (2013). Módulo de condiciones socioeconómicas 2012. México: INEGI.

Instituto Nacional de Estadística y Geografía (INEGI). (2014). Módulo de bienestar autorreportado BIARE. México: INEGI.

Instituto Nacional de Estadística y Geografía (INEGI). (2015a). Encuesta Nacional de Ingresos y Gastos de los Hogares (2014). Módulo de condiciones socioeconómicas: descripción de la base de datos. México: INEGI.

Instituto Nacional de Estadística y Geografía (INEGI). (2015b). Encuesta Nacional de Ingresos y Gastos de los Hogares (2014). Módulo de condiciones socioeconómicas 2014: microdatos. Módulo de bienestar autorreportado 2014: microdatos. México: INEGI.

Instituto Nacional de Estadística y Geografía (INEGI). (2018). Instituto Nacional de Estadística y Geografía. Recuperado de http://www.beta.inegi.org.mx/ proyectos/investigacion/bienestar/piloto/

Instituto Nacional de Estadística y Geografía (INEGI). (2019a). Encuesta Intercensal 2015. Tabulados. México: INEGI.

Instituto Nacional de Estadística y Geografía (INEGI). (2019b). Encuesta Nacional de Victimización y Percepción sobre Seguridad Pública (ENVIPE) 2019. Tabulados. México: INEGI. 
Insulza, J. (2014). El problema de las drogas en las Américas: estudios. Washington: Organización de los Estados Americanos.

Jaitman, L. (2015). Los costos del crimen y la violencia en el bienestar en América Latina y el Caribe. Washington, D. C: Banco Interamericano de Desarrollo.

Lissardy, G. (12 de julio de 2019). Por qué América Latina es “la región más desigual del planeta”. BBC News Mundo. Recuperado de https://www.bbc. $\mathrm{com} /$ mundo/noticias-america-latina-51390621

Martin, G., y Ceballos Arévalo, M. (2004). Bogotá: anatomía de una transformación. Políticas de seguridad ciudadana 1995-2003. Bogotá: Editorial Pontificia Universidad Javeriana.

Martínez Ferrer, B., Ávila Guerrero, M. E., Vera Jiménez, J. A., Bahena Rivera, A., y Musitu Ochoa, G. (2016). Satisfacción con la vida, victimización y percepción de inseguridad en Morelos, México. Salud Pública de México, 58(1), 16-24. doi: http://dx.doi.org/10.21149/spm.v58i1.7663

Mockus, A., Murraín, H., y Villa, M. (2012). Introducción. En A. Mockus, H. Murraín y M. Villa (coords.), Antípodas de la violencia. Desafíos de cultura ciudadana para la crisis de (in)seguridad en América Latina (pp. 19-27). Washington, D. C.: Banco Interamericano de Desarrollo.

Muggah, R. (2017). El auge de la seguridad ciudadana en América Latina y el Caribe. Revue Internationale de Politique de Développement (9), 291-322. doi: $10.4000 /$ poldev. 2377

Organización Mundial de la Salud (OMS). (2002). Informe mundial sobre la violencia y la salud: resumen. Washington, D. C.: Organización Panamericana de la Salud, Oficina Regional para las Américas de la Organización Mundial de la Salud.

Pegoraro, J. S. (2002). Las políticas de seguridad y la participación comunitaria en el marco de la violencia social. En Consejo Latinoamericano de Ciencias Sociales, Violencia, sociedad y justicia en América Latina (pp. 29-55). Buenos Aires: CLACSO.

Ramos García, J. (2005). Seguridad ciudadana y la seguridad nacional en México: hacia un marco conceptual. Revista Mexicana de Ciencias Políticas y Sociales, 47 (194), 33-52.

Ruiz, J., y Murraín, H. (2012). La cultura ciudadana y la agenda de políticas de seguridad. En A. Mockus, H. Murraín y M. Villa (coords.), Antípodas de la violencia. Desafíos de cultura ciudadana para la crisis de (in)seguridad en América Latina (pp. 1-21). Washington, D. C.: Banco Interamericano de Desarrollo.

Salazar, M., y Castro, M. (1998). Respuesta a la criminalidad y la violencia en Colombia: una visión desde lo público. Coyuntura Social (18), 235-248.

San Martín, C. (2012). Las representaciones sociales de la seguridad ciudadana en los vecinos de la comuna de Melipilla, Chile. Psicoperspectivas, 12(1), 7294. doi: 10.5027/psicoperspectivas-Vol12-Issue1-fulltext-219

Secretariado Ejecutivo del Sistema Nacional de Seguridad Pública. (2020). Gobierno de México. Recuperado de https://www.gob.mx/sesnsp/acciones-y-programas/victimas-nueva-metodologia?state=published 
Shaw, C., y Mckay, H. (2006). Juvenile delinquency and urban areas. En F. Cullen y R. Agnew, Criminological Theory: Past to Present (pp. 95-108). Los Ángeles: Roxbury.

Sozzo, M. (2016). Park, Shaw y McKay y la mirada sociológica sobre el delito en la Escuela de Chicago. Delito y Sociedad 1(25), 107-114. doi: 10.14409/dys. v1i25.5881

Sutton , H., y Álvarez, L. (2017). How do neighbourhood characteristics affect crime? En Banco Interamericano del Desarrollo, Restoring Paradise in the Caribbean: Combatting Violence with Numbers (pp. 99-109). Washington: BID.

Sutton, H., y Godínez, L. (2017). What the Caribbean is doing to reduce crime compared to the evidence of what works internationally. En Banco Interamericano del Desarrollo, Restoring Paradise in the Caribbean: Combatting Violence with Numbers (pp. 211-235). Washington: BID.

Vozmediano, L., y San Juan, C. (2010). Criminología ambiental: ecología del delito y de la seguridad. Barcelona: Editorial UOC.

Wilson, J., y Herrnstein, R. (1998). Crime \& Human Nature: The Definitive Study of the Causes of Crime. Nueva York: Simon and Schuster.

Wilson, J., y Kelling, G. (1982). The police and neighborhood safety: broken windows. Atlantic Monthly (127), 29-38. 